\title{
Physiological analysis reveals relatively higher salt tolerance in roots of Ilex integra than in those of Ilex purpurea
}

\author{
Yongfan $\mathrm{Yu}^{1} \cdot$ Min Zhang ${ }^{2} \cdot$ Jianyuan Feng ${ }^{1}$. \\ Sujing Sun ${ }^{1} \cdot$ Peng Zhou $^{2} \cdot$ Jiading Yang $^{1}$
}

Received: 10 May 2021 / Accepted: 14 June 2021 / Published online: 21 September 2021

(C) The Author(s) 2021

\begin{abstract}
Determining the responses of candidate plants to salt stress is a prerequisite for selecting and breeding suitable plants with high salt tolerance to grow in coastal mudflat areas with high salinity. Here, 2-year cutting seedlings of Ilex purpurea Hassk. (local species) and I. integra Thunb. (introduced species) were grown in pots in a glasshouse and irrigated with a Hoagland- $\mathrm{NaCl}$ solution at 0,24 , and $48 \mathrm{~h}$. Root samples were collected at $0,1,6,24$, and $72 \mathrm{~h}$, and concentration of $\mathrm{Na}^{+}$ion; content of proline, soluble carbohydrate, malondialdehyde (MDA), $\mathrm{H}_{2} \mathrm{O}_{2}$ and ascorbate; and activity of three key antioxidative enzymes were measured. Roots of I. integra accumulated relatively less $\mathrm{Na}^{+}$and had less membrane lipid peroxidation and $\mathrm{H}_{2} \mathrm{O}_{2}$ during salt stress, thus indicating a relatively higher salt tolerance than roots of I. purpurea. Values for ascorbate content and antioxidant enzymatic activity suggest that the antioxidant ascorbate and antioxidative catalase may play substantial roles for
\end{abstract}

Project funding The work was supported by the Key Research and Development Program of Jiangsu Province (Modern agriculture) (BE2018400) and by Innovation Capacity Building Plan (Science and Technology Facilities) - Independent Research Fund for Research Institutes of Public Welfare of Jiangsu Province (BM2018022-6).

The online version is available at http://www.springerlink.com

Corresponding editor: Tao Xu.

Jiading Yang

jdyang33@njfu.edu.cn

1 Co-Innovation Center for Sustainable Forestry in Southern China, College of Biology and the Environment, Nanjing Forestry University, Nanjing 210037, People's Republic of China

2 Jiangsu Academy of Forestry, Nanjing 211153, People's Republic of China scavenging reactive oxygen species in I. integra roots during salt treatment. Thus, I. integra is apparently more suitable for growing in local highly saline coastal mudflats.

Keywords Salt tolerance - Ilex purpurea Ilex integra . Lipid peroxidation $\cdot \mathrm{Na}^{+}$accumulation $\cdot$ Antioxidant capacity

\section{Introduction}

Soil salinity causes massive agricultural and horticultural losses worldwide and restricts the distribution of wild species (Zhao et al. 2020). Elucidating the physiological, metabolic, and biochemical responses of plants to salt stress and the mechanisms that contribute to salt tolerance is critical for developing and cultivating salt-tolerant plants and ensuring food and ecological security. Soil salinity inhibits plant growth and development mainly through two phases. The first is osmotic stress, which inhibits plant uptake of water by lowering the external water potential, and the second is ionic toxicity or imbalance, which is primarily associated with excessive accumulation of $\mathrm{Na}^{+}$in plant cells (Munns and Tester 2008). Ionic toxicity is generally thought to have a relatively later onset than osmotic stress and to operate at a timescale of days, weeks or even months (Munns 2002). Prolonged salt stress may result in arrested shoot growth and finally plant death. Among plant organs, roots are usually exposed to salt or to drying soil directly, so their capacity to tolerate osmotic stress imposed by salinity and take up or exclude ions is closely associated with plant performance in salt environments. Theoretically, increasing root tolerance to both the osmotic and ionic components of salinity stress may synergistically improve plant productivity under salt stress (Munns and Tester 2008). 
To maintain a low intracellular osmotic potential under high salinity, plants have evolved physiological or metabolic strategies to accumulate osmolytes such as proline, glycine betaine, soluble sugars, polyamines, and proteins from the late embryogenesis abundant (LEA) superfamily (Verslues et al. 2006). Proline is known to play a dominant role in osmotic adjustment under salt stress (Mansour and Ali 2017) and may act to stabilize proteins and membrane structures or scavenge reactive oxygen species (ROS) to attenuate oxidative stress under high salinity (Ashraf and Foolad 2007; Ben Rejeb et al. 2014). However, a high level of proline accumulation is not always correlated with osmotolerance as demonstrated by an Arabidopsis mutant that accumulates higher proline levels and is hypersensitive to salt (Liu and Zhu 1997). A genome-wide association analysis revealed that only proline accumulation in roots, not in leaves, was positively correlated with salinity tolerance in Medicago truncatula (Kang et al. 2019), indicating that different organs with proline accumulation may have differential role in plant salt tolerance.

As aerobic organisms, plants inevitably form reactive oxygen species (ROS), predominantly as $\mathrm{H}_{2} \mathrm{O}_{2}$ when stressed by high salinity (Pang and Wang 2008). ROS at low levels may act as signal molecules, but they can cause oxidative damage to membrane lipids, proteins, nucleic acids and pigments when over-produced (Noctor and Foyer 1998; Zhao et al. 2020), as occurs during salt stress (Gupta and Huang 2014). Although plants have well-developed enzymatic and non-enzymatic antioxidative systems to control ROS levels (Gupta and Huang 2014), the balance between producing and quenching ROS may be destroyed when scavenging systems are disrupted by salt stress. Excess production or accumulation of ROS, alone or in combination with other metabolites, can cause lipid peroxidation, protein modification, DNA strand breakage and cell death (Biswas and Mano 2015; Locato and De Gara 2018). Plant performance under salinity stress can be improved by increasing either the plant's capacity to scavenge ROS, enzymatically or non-enzymatically. For example, overexpression of certain antioxidant enzyme genes improved the growth of saltstressed plants (Diaz-Vivancos et al. 2013; Eltayeb et al. 2007; Prashanth et al. 2008), and plants that synthesize more glutathione had greater salinity tolerance (Roxas et al. 1997; Ruiz and Blumwald 2002).

The coastal mudflats in China total $2.114 \times 10^{6}$ ha of intermittent strips along 32,000 km of coastline (Yang and Wang 2015). They are regarded as important alternative land sources for agriculture, but in reality the high salinity and low fertility are not suitable for most crops (Bai et al. 2018; Hniličková et al. 2019). To ameliorate these poor conditions, numerous engineering, physical, chemical, agronomic and biological strategies have been developed (Wan et al. 2017). The agronomic and biological ameliorations aim to increase soil organic ingredients and/ or improve salt resistance of selected plants/crops. Such biological strategies are thought to be the most economic and sustainable because halophytes not only absorb soil salts and improve physicochemical properties of soils, but also promote habitats for microbes and animals as saline agriculture and forest become established in coastal mudflats (Yang and Wang 2015). However, finding suitable halophytes or plants with salt tolerance for the different local environments of coastal mudflats all over world is a challenge.

Selecting or breeding salt-tolerant species that can be grown on the coastal mudflat areas is essential for primary utilization of that kind of land with high salinity. However, because salt tolerance is a comprehensive response, a successful strategy to improve salt tolerance depends largely on targeting the key salt tolerance mechanisms for a specific plant species (Roy et al. 2014). Salt tolerance of annual crops can be assessed by comparing biomass production by the plant growing in saline conditions to that when grown in control conditions over a certain time. However, for woody plants, usually with a relatively slower growth rate, other ways than biomass comparison, e.g., simple and quick physiological variables may be employed to compare salt tolerance (Baraldi et al. 2019).

The search for suitable plants to grow in a local coastal mudflat can reasonably start with testing endemic or introduced plants for their salt tolerance and assessing their potential to add high value. We chose two Ilex species, which are evergreen, woody plants, and confer more ecological advantages than annual plants in mudflat amelioration. Ilex purpurea Hassk. is a widely distributed endemic in Yangzi River valley and valued for landscaping for its bright red fruits (Shi et al. 2019). It also has high resistance to wind and can tolerate wet soils but not extended flooding. I. integra Thunb., distributed in the coastal regions of Zhejiang and Fujian provinces in southeastern China and southern areas of Japan and South Korea (Xu et al. 2007), is speculated to have high salt tolerance and is being considered as a suitable import for the coastal mudflat in Jiangsu Province in eastern China, which totals $0.6 \times 10^{6} \mathrm{ha}$, about one fourth of the total coastal mudflat area in China (Wan et al. 2017). Because little is known about the physiological responses of the two species to salt stress or differences in salt tolerance, in the present study, we grew 2-year old cutting seedlings of I. purpurea and I. integra in a glasshouse and irrigated the soil with a Hoagland- $\mathrm{NaCl}$ solution. After different durations of the salt treatment, the roots were sampled to measure concentrations of $\mathrm{Na}^{+}$, contents of proline, soluble carbohydrate, malondialdehyde (MDA), $\mathrm{H}_{2} \mathrm{O}_{2}$ and ascorbate, and activities of three antioxidative enzymes. 


\section{Materials and methods}

\section{Plant materials and salt treatment}

Two-year plants of I. purpurea and I. integra, started from cuttings and about 50-60 cm tall growing in a local nursery field, were dug up and the soil washed from the roots with tap water. Plants were then transplanted into a mixture of garden soil and perlite (1:1 v/v) in 1-L pots (1 plant per pot) and grown in a glasshouse at the Baima Experimental Station $\left(31^{\circ} 6^{\prime} \mathrm{N}, 119^{\circ} 18^{\prime} \mathrm{E}\right)$ of Nanjing Forestry University. Half-strength Hoagland solution (Hoagland and Arnon 1950) was applied to the top of the soil in the pots $(500 \mathrm{~mL}$ per pot) every $4 \mathrm{~d}$ for 2 weeks; the soil surface did not dry out during this time. The soil in each pot was then irrigated with $500 \mathrm{~mL}$ of salt solution (half-strength Hoagland solution containing $250 \mathrm{mM} \mathrm{NaCl}$ ) (between 9:00 to 10:00 am) at time 0 (first treatment), 24 and $48 \mathrm{~h}$ to make sure that the soil was totally saturated with the salt solution; any excess solution drained through the holes in the bottom of the pots. A total of 75 plants were included in salt treatment for each species.

\section{Sample harvesting}

Nine plants were selected randomly at time $0,1,6,24$ and $72 \mathrm{~h}$, then separated randomly into three groups as three biological replicates. The root systems of plants were carefully dug out, quickly washed with tap water to remove any soil and separated into two parts. One part was frozen in liquid $\mathrm{N}$, then stored at $-80^{\circ} \mathrm{C}$ until further ground to fine powder using a freezer mill. The second part was dried at $105{ }^{\circ} \mathrm{C}$ for $3 \mathrm{~h}$, then at $65^{\circ} \mathrm{C}$ for $48 \mathrm{~h}$, then ground to a fine powder using an electric mill.

\section{Measurements}

\section{Sodium ion concentration}

The dry powder sample $(0.3 \mathrm{~g})$ was digested with $10 \mathrm{~mL}$ acid mixture of $15.6 \mathrm{~N} \mathrm{HNO}_{3}$ and $11.65 \mathrm{~N} \mathrm{HClO}_{4}(4: 1$ $\mathrm{v} / \mathrm{v}$ ) at room temperature for $48 \mathrm{~h}$. The digestion volume was then condensed to $2 \mathrm{~mL}$, diluted in a $50 \mathrm{~mL}$ volumetric flask with $48 \mathrm{~mL}$ deionized water, then filtered through a $0.45-\mu \mathrm{m}$ membrane filter. The concentration of sodium ion was determined with a flame atomic absorption spectrometer (AA900T, Perkin Elmer, USA) and expressed in $\mathrm{mg} \mathrm{g}^{-1}$ dry mass as mean of 3 sample replicates.

\section{Malondialdehyde}

The level of membrane lipid peroxidation in samples was estimated by measuring malondialdehyde (MDA) content.
About $0.3 \mathrm{~g}$ of the frozen-root powder was homogenized in $1 \mathrm{~mL}$ of $80 \%(\mathrm{v} / \mathrm{v})$ cold ethanol on ice and then centrifuged at $16,000 \times g$ for $20 \mathrm{~min}$ at $4{ }^{\circ} \mathrm{C}$. The supernatant $(0.6 \mathrm{~mL})$ was mixed with $0.6 \mathrm{~mL}$ of $20 \%(\mathrm{w} / \mathrm{v})$ trichloroacetic acid containing $0.65 \%(\mathrm{w} / \mathrm{v})$ thiobarbituric acid. The mixture was heated at $95^{\circ} \mathrm{C}$ for $30 \mathrm{~min}$, then cooled quickly in an ice bath and centrifuged at $10,000 \times g$ for $10 \mathrm{~min}$. The absorbance of the supernatant was measured at $532 \mathrm{~nm}$ and the amount of MDA in the supernatant was calculated as described previously (Campo et al. 2014).

\section{Soluble sugar and proline}

The frozen-root powder was homogenized with $80 \%$ $(\mathrm{v} / \mathrm{v})$ ethanol at room temperature. After centrifugation at $16,000 \times \mathrm{g}$ for $10 \mathrm{~min}$, the supernatant was decanted to a clean tube. The pellet was then subjected to the extraction process two more times, and the supernatants bulked. Total soluble sugar in the supernatant was determined using the anthrone-sulfuric acid method (McCready et al. 1950). Proline was also determined spectrophotometrically using the ninhydrin method (Bates et al. 1973).

$\mathrm{H}_{2} \mathrm{O}_{2}$

Based on the modified method (Ferguson et al. 1983), we homogenized the frozen-root powder (about fresh mass $1.0 \mathrm{~g}$ ) in $3 \mathrm{~mL}$ cold acetone, centrifuged the samples at $5000 \times g$ for $10 \mathrm{~min}$ at $4{ }^{\circ} \mathrm{C}$, and added $0.2 \mathrm{~mL}$ of the supernatant to $0.8 \mathrm{~mL}$ cold acetone, which was then mixed with $0.1 \mathrm{~mL}$ of $20 \% \mathrm{TiCl}_{4}-\mathrm{HCl}$ solution and $0.2 \mathrm{~mL}$ strong ammonia hydroxide, and centrifuged at $3000 \times g$ for $10 \mathrm{~min}$. The resultant peroxide-Ti compound was washed with acetone 3-5 times, dissolved in $3 \mathrm{~mL}$ of $2 \mathrm{M} \mathrm{H}_{2} \mathrm{SO}_{4}$, and the absorbance measured at $410 \mathrm{~nm}$. The content of $\mathrm{H}_{2} \mathrm{O}_{2}\left(\mu \mathrm{mol} \mathrm{g}{ }^{-1}\right.$ fresh mass) was determined using a standard curve.

\section{Ascorbate}

Ascorbate contents were determined according to a previous method (Kampfenkel et al. 1995) with minor modifications. About $0.3 \mathrm{~g}$ of frozen-root powder was homogenized in ice-cold mortar with $0.6 \mathrm{~mL}$ cold solution of $6 \%(\mathrm{w} / \mathrm{v})$ trichloroacetic acid (TCA). The content of reduced ascorbate (ASA) in TCA extract was determined by its capacity to reduce ferric ion to ferrous ion and was measured based on the characteristic absorbance at $525 \mathrm{~nm}$ of a complex formed by ferrous ion and $\alpha$ - $\alpha^{\prime}$-bipyridl. The total ascorbate pool (ASA-pool) was measured after adding excess dithiothreitol to TCA extracts to reduce the oxidized ascorbate (dehydroascorbate, DHA) to ASA (Gillespie and Ainsworth 2007). 
Catalase, peroxidase dismutase and superoxide dismutatase activity

About $0.2 \mathrm{~g}$ of frozen-root powder was homogenized in $2.5 \mathrm{~mL}$ cold extraction buffer $(50 \mathrm{mM}$ sodium phosphate buffer $\mathrm{pH} 7.0$, containing $1 \% \mathrm{~m} / \mathrm{v}$ polyvinylpyrrolidone), then centrifuged at $15,000 \times g$ for $20 \mathrm{~min}$ at $4{ }^{\circ} \mathrm{C}$. The supernatant was then used to assay catalase (CAT; EC 1.11.1.6) and guaiacol peroxidase (POD; EC 1.11.1.7) activity. The same process was conducted for extracting superoxide dismutase (SOD; EC 1.15.1.1) except that the extraction buffer was $50 \mathrm{mM}$ phosphate buffer $(\mathrm{pH} 7.8)$ containing $2 \%(\mathrm{~m} / \mathrm{v})$ polyvinylpyrrolidone, $0.3 \%(\mathrm{v} / \mathrm{v})$ Triton X-100, and $0.1 \mathrm{mM}$ EDTA. The soluble protein concentration of enzyme solutions was determined using the Bradford method with bovine serum albumin as the standard (Bradford 1976).

Activities of CAT and POD were measured according to a previous report (Liu and Huang 2000). One unit of activity was defined as an absorbance change of 0.01 per min at $240 \mathrm{~nm}$ for CAT and $470 \mathrm{~nm}$ for POD, respectively. The activity of SOD was determined by measuring the inhibition of the photoreduction of nitro blue tetrazolium (NBT) (Cavalcanti et al. 2004); one unit of SOD activity was defined as the amount of enzyme that inhibits $50 \%$ of NBT photoreduction. Absorbance of the solutions described was measured using a UV-1900 UV-Visible Spectrophotometer (Shimadzu Corp., Kyoto, Japan).

\section{Statistical analyses}

Means were subjected to analysis of variance according to the model for completely randomized design using SPSS version 25.0 (IBM, Armonk, NY, USA). Differences between means \pm SD of two species at a certain sampling time were evaluated by Student's $t$-test at 0.05 probability level. Differences among means \pm SD at various sampling times for a certain species were first estimated by one-way variance analysis (ANOVA) and then evaluated by Duncan's multiple range test at 0.05 probability level.

\section{Results}

\section{Variations of $\mathrm{Na}^{+}$concentrations in the two Ilex species}

Before the salt treatment started, the $\mathrm{Na}^{+}$concentration in I. integra roots was $1.30 \mathrm{mg} \mathrm{g}^{-1} \mathrm{DW}$ (dry weight), 2.67fold higher than in $I$. purpurea roots $\left(0.48 \mathrm{mg} \mathrm{g}^{-1}\right)$ (Fig. 1). With increasing duration of the salt treatment, the $\mathrm{Na}^{+}$ concentrations in I. integra roots gradually increased from $1.43 \mathrm{mg} \mathrm{g}^{-1}$ after $1 \mathrm{~h}$ of treatment to $2.01 \mathrm{mg} \mathrm{g}^{-1}$ after $24 \mathrm{~h}$. After $72 \mathrm{~h}$ salt treatment, the $\mathrm{Na}^{+}$concentration in I. integra roots was 1.76-fold higher than before the treatment.

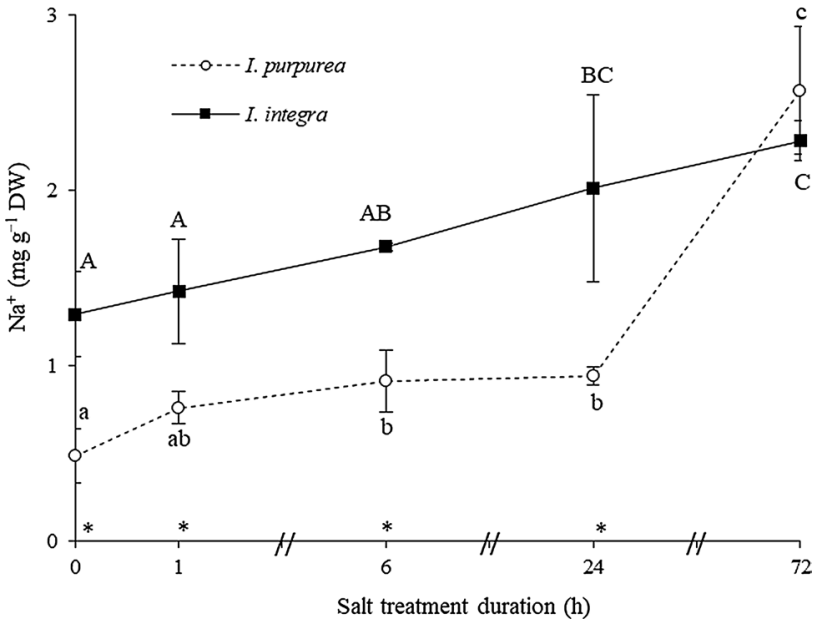

Fig. 1 Mean $( \pm \mathrm{SD}) \mathrm{Na}^{+}$concentration in roots of two Ilex species after different durations of salt treatment. An asterisk by the $x$-axis indicates a significant difference in concentration between the two species at that sampling time based on Student's $t$-test $(p<0.05)$. A significant difference among concentrations at the sampling times is indicated by different capital letters for I. integra and by different lowercase letters for I. purpurea based on an ANOVA and Duncan's multiple range test $(p<0.05)(n=3)$

However, although $\mathrm{Na}^{+}$concentration in I. purpurea roots only increased slightly from $0.76 \mathrm{mg} \mathrm{g}^{-1}$ after $1 \mathrm{~h}$ of treatment to $0.94 \mathrm{mg} \mathrm{g}^{-1}$ after $24 \mathrm{~h}$, the concentration increased sharply after $72 \mathrm{~h}$ to $2.57 \mathrm{mg} \mathrm{g}^{-1}, 5.31$-fold higher than before the treatment, and was thus similar to the level in the roots of I. integra.

\section{Malondialdehyde (MDA) concentrations}

Malondialdehyde (MDA) was present at similar levels in roots of I. purpurea and I. integra (13.2 and $11.8 \mu \mathrm{mol} \mathrm{g}^{-1}$ FW (fresh weight), respectively) before the salt treatment (Fig. 2). MDA concentrations in roots of both plants increased gradually during salt treatment and peaked at $24 \mathrm{~h}$ (28.7 $\mu \mathrm{mol} \mathrm{g}^{-1} \mathrm{FW}$ for I. purpurea and $22.0 \mu \mathrm{mol} \mathrm{g}{ }^{-1} \mathrm{FW}$ for I. integra, respectively). Notably, the MDA concentration in I. purpurea roots during salt treatment was always higher, indicating more membrane damage in I. purpurea roots.

\section{Proline and total soluble sugars}

The concentration of proline in roots of I. purpurea and $I$. integra did not differ significantly before salt treatments (1.63 vs $1.29 \mu \mathrm{g} \mathrm{g}^{-1} \mathrm{FW}$, respectively) and increased similarly during the salt treatment (Fig. 3a). However, the proline concentration was significantly higher in I. integra roots after 1,6 , and $24 \mathrm{~h}$; by $72 \mathrm{~h}$, the concentrations no longer differed significantly. For total soluble sugars, the concentration in $I$. integra differed significantly from that in I. purpurea roots at 


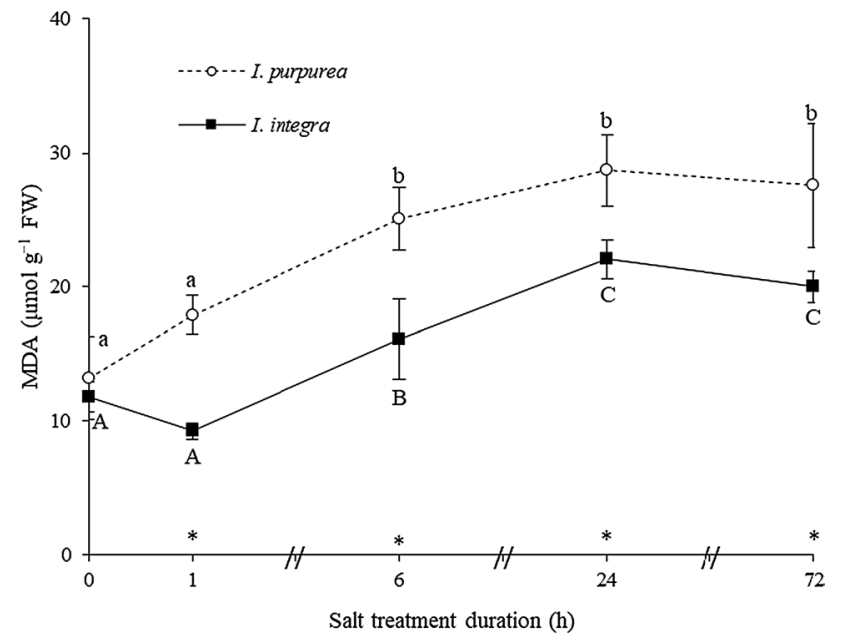

Fig. 2 Mean $( \pm S D)$ malondialdehyde (MDA) concentrations in roots of two Ilex species after different durations of salt treatment. An asterisk by the $x$-axis indicates a significant difference in concentration between the two species at that sampling time based on Student's $t$-test $(p<0.05)$. A significant difference among concentrations at the sampling times is indicated by different capital letters for $I$. integra and by different lowercase letters for I. purpurea based on an ANOVA and Duncan's multiple range test $(p<0.05)(n=3)$

$0 \mathrm{~h}$ (2.05 $\mathrm{mg} \mathrm{g}^{-1} \mathrm{FW}$ vs $2.20 \mathrm{mg} \mathrm{g}^{-1} \mathrm{FW}$, respectively) and throughout the salt treatment (Fig. 3b), but the level did not differ significantly in its own roots regardless of the duration of the salt exposure. In roots of I. purpurea, however, the total sugars increased until $6 \mathrm{~h}\left(3.80 \mathrm{mg} \mathrm{g}^{-1} \mathrm{FW}\right)$, then declined and leveled off to $3.28 \mathrm{mg} \mathrm{g}^{-1} \mathrm{FW}$ at $72 \mathrm{~h}$; after the salt treatment began, the levels were always significantly higher than in I. integra (Fig. 3b).

\section{$\mathrm{H}_{2} \mathrm{O}_{2}$ contents}

Before the salt treatment, the $\mathrm{H}_{2} \mathrm{O}_{2}$ content in I. integra roots was significantly higher than in I. purpurea roots (Fig. 4). In both species, $\mathrm{H}_{2} \mathrm{O}_{2}$ content increased through $6 \mathrm{~h}$ of exposure, then declined through $72 \mathrm{~h}$. Notably, the $\mathrm{H}_{2} \mathrm{O}_{2}$ content in I. integra roots was significantly lower than in I. purpurea roots by $72 \mathrm{~h}$, the opposite from $0 \mathrm{~h}$, indicating that more $\mathrm{H}_{2} \mathrm{O}_{2}$ was accumulated in I. purpurea roots after extension of salt treatments.

\section{Ascorbate pool and reduced-ascorbate content}

The ascorbate (ASA) pool in roots of both plants was similar from 0 to $24 \mathrm{~h}$ of salt exposure (Fig. 5a). Compared to the level at $0 \mathrm{~h}$, the ascorbate pool in I. purpurea roots was significantly lower after $1 \mathrm{~h}$ of salt treatment, then slightly higher as the duration increased but not significantly higher until after $72 \mathrm{~h}$. The ASA pool in I. integra roots did not differ significantly from the 0 -h level until
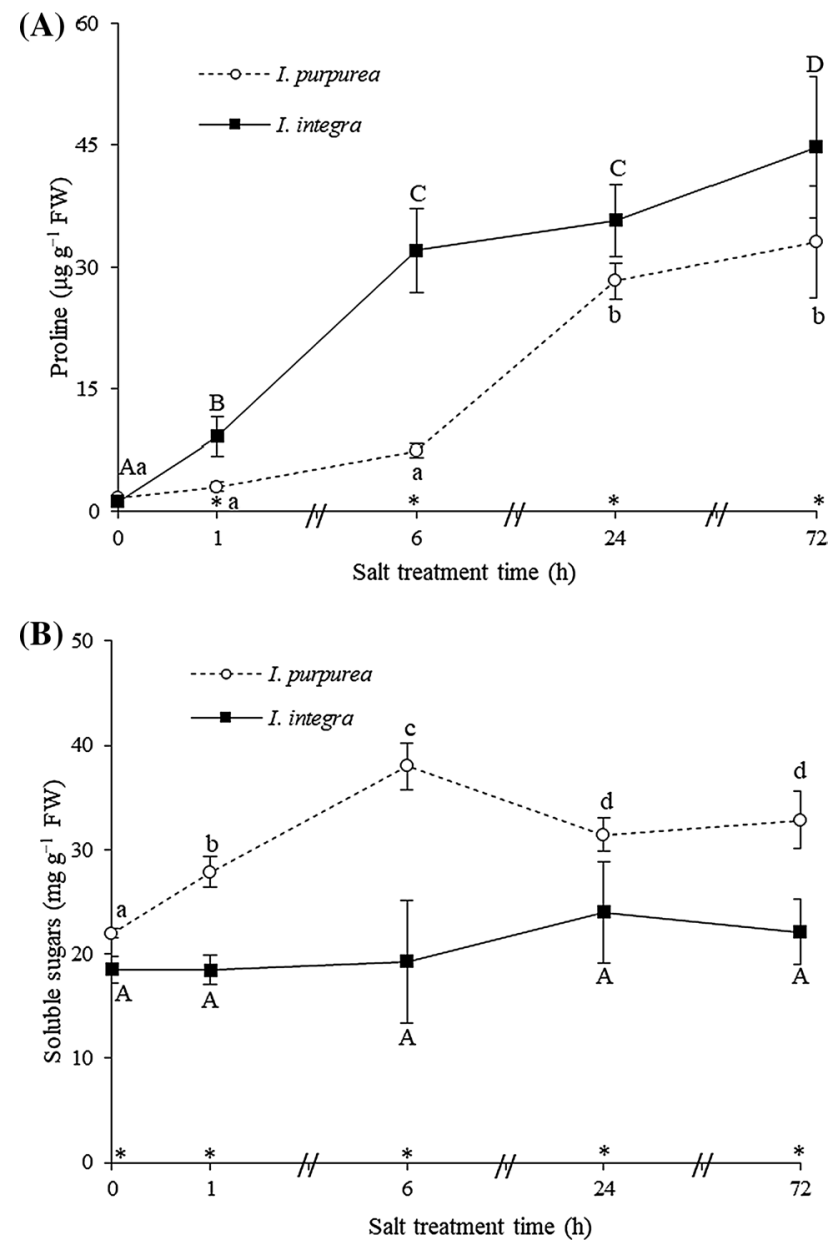

Fig. 3 Concentrations of proline $\mathbf{a}$ and soluble sugars $\mathbf{b}$ in roots of two Ilex species after different durations of salt treatment. An asterisk by the $x$-axis indicates a significant difference in concentration between the two species at that sampling time based on Student's $t$-test $(p<0.05)$. A significant difference among concentrations for at the sampling times is indicated by different capital letters for I. integra and by different lowercase letters for I. purpurea based on an ANOVA and Duncan's multiple range test $(p<0.05)(n=3)$

24 and $72 \mathrm{~h}$ when it was significantly higher. Although the level in roots of both species did not differ significantly from 0 to $6 \mathrm{~h}$, the ASA pool in I. integra roots was significantly higher than in I. purpurea roots after 24 and $72 \mathrm{~h}$. Thus, I. integra roots may have a relatively higher capacity to increase its ASA pool in response to extended salt exposure. As shown in Fig. 5b, the reduced-ASA content in $I$. purpurea roots decreased gradually from $0.23 \mu \mathrm{mol} \mathrm{g}$ at $0 \mathrm{~h}$ to $0.09 \mu \mathrm{mol} \mathrm{g}^{-1}$ at $72 \mathrm{~h}$ of salt treatment, while reduced-ASA in I. integra roots decreased sharply from 0.22 at $0 \mathrm{~h}$ to $0.06 \mu \mathrm{mol} \mathrm{g}{ }^{-1}$ after $1 \mathrm{~h}$ of salt treatment, then partially recovered to $0.13 \mu \mathrm{mol} \mathrm{g}^{-1}$ at $6 \mathrm{~h}$, then decreased gradually until $72 \mathrm{~h}$ of salt treatment, when it did not differ significantly from the lowest level at $1 \mathrm{~h}$. 


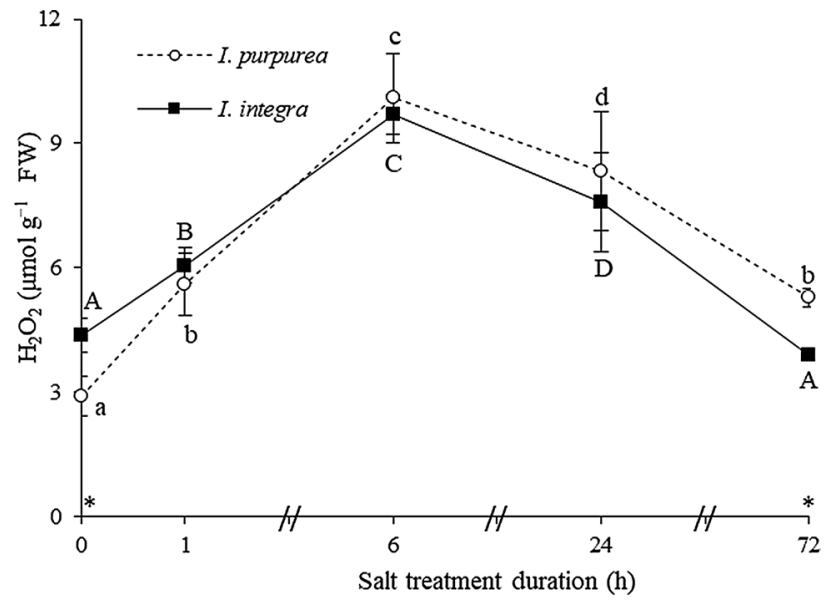

Fig. 4 Mean $( \pm S D)$ content of $\mathrm{H}_{2} \mathrm{O}_{2}$ in roots of two Ilex species after different durations of salt treatment. An asterisk by the $x$-axis indicates a significant difference in concentration between the two species at that sampling time based on Student's $t$-test $(p<0.05)$. A significant difference among concentrations at the sampling times is indicated by different capital letters for I. integra and by different lowercase letters for I. purpurea based on an ANOVA and Duncan's multiple range test $(p<0.05)(n=3)$

\section{Activity of antioxidant enzymes}

SOD and POD were significantly higher in I. purpurea roots than in I. integra roots at all times (Fig. 6a, b). In I. purpurea roots, SOD activity was highest $\left(2.40 \mathrm{U} \mathrm{mg}^{-1}\right.$ protein) before the salt treatment began, then decreased significantly to 1.33 $\mathrm{U} \mathrm{mg}^{-1}$ protein and did not then change significantly for the rest of the experiment. In I. integra roots, SOD activity increased from $0.03 \mathrm{U} \mathrm{mg}^{-1}$ protein at $0 \mathrm{~h}$ to maximum values between 6 and $24 \mathrm{~h}\left(0.55 \mathrm{U} \mathrm{mg}^{-1}\right.$ protein). For I. integra, the POD activities were at similar levels in roots before and during salt treatments, possibly indicating that POD is not critical for the response of I. integra roots to salinity. However, POD activity in I. purpurea roots decreased after $1 \mathrm{~h}$ of salt exposure, then increased gradually with the duration of the salt stress. Interestingly, although CAT activity was significantly higher in I. purpurea roots than in I. integra roots before the salt treatment (Fig. 6c), it decreased in $I$. purpurea roots but increased in I. integra roots during the salt exposure. CAT activity was significantly higher in $I$. integra roots, than that in I. purpurea roots at $72 \mathrm{~h}$ of salt treatment, indicating a higher capacity for scavenging $\mathrm{H}_{2} \mathrm{O}_{2}$.

\section{Discussion}

Before the salt treatment began, roots of I. integra had a higher concentration of $\mathrm{Na}^{+}$than those of I. purpurea, consistent with the natural distribution of I. integra in coastal regions with higher salt. During the salt treatments, $\mathrm{Na}^{+}$
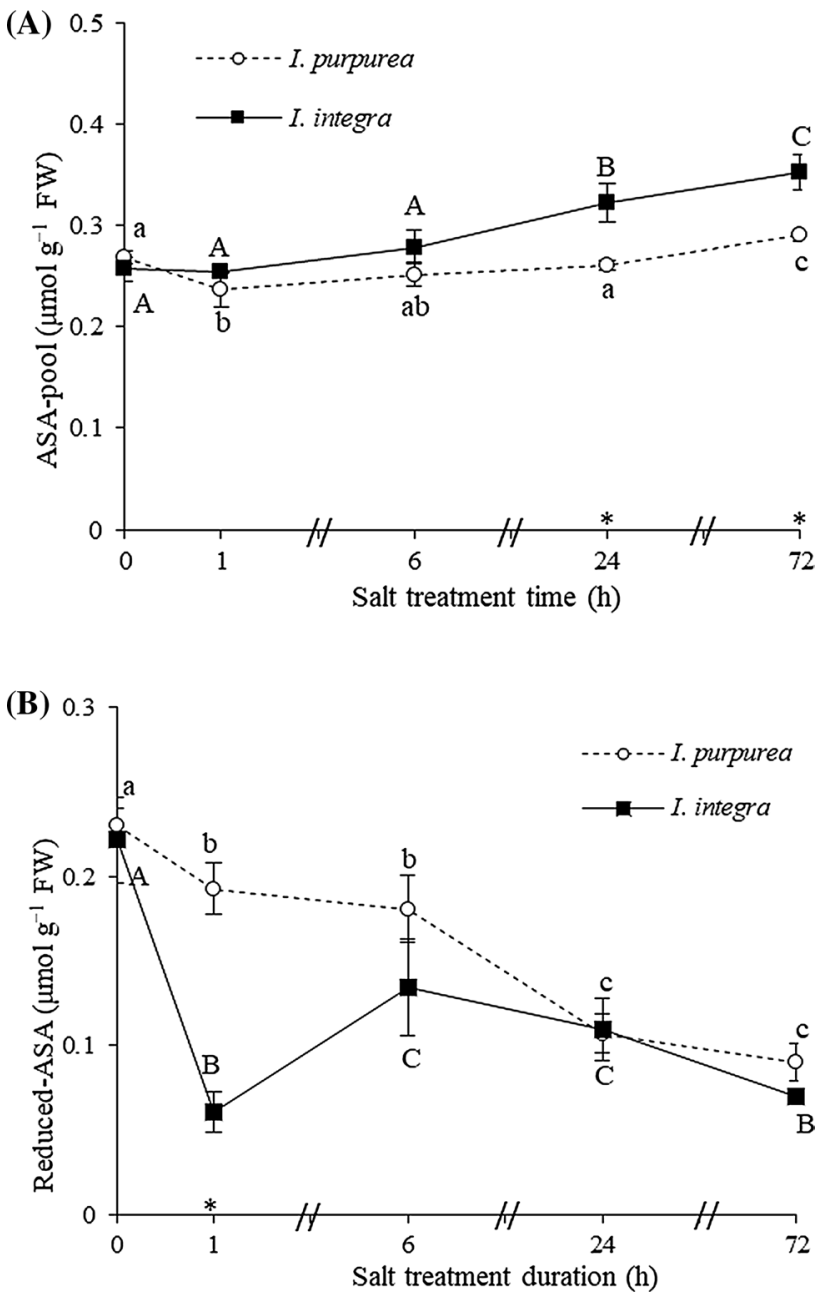

Fig. 5 Mean $( \pm S D)$ total ascorbate (ASA-pool) and reduced ascorbate (ASA) in roots of two Ilex species after different durations of salt treatment. Values are means $\pm \mathrm{SD}(n=3)$. An asterisk by the $x$-axis indicates a significant difference in concentration between the two species at that sampling time based on Student's $t$-test $(p<0.05)$. A significant difference among concentrations at the sampling times is indicated by different capital letters for I. integra and by different lowercase letters for I. purpurea based on an ANOVA and Duncan's multiple range test $(p<0.05)(n=3)$

concentrations in the roots of the two Ilex species continued to differ. Although the concentration increased gradually in I. integra roots with extended salt stress, after $72 \mathrm{~h}$, it was only 1.76 -fold higher than before the treatment began. In $I$. purpurea, $\mathrm{Na}^{+}$concentration only increased slightly after $24 \mathrm{~h}$ of salt exposure, but it sharply increased after $72 \mathrm{~h}$ to 5.31-fold higher than at $0 \mathrm{~h}$, thus reaching to a level similar to that in I. integra. These results clearly indicated that $I$. integra root responded to exogenous salinity in a controlled way and might encounter mainly osmotic stress during $72 \mathrm{~h}$ of salt exposure. However, in I. purpurea roots, osmotic stress may persist during $24 \mathrm{~h}$ of salt stress because there was no obvious increase in $\mathrm{Na}^{+}$concentration, after $72 \mathrm{~h}$ 

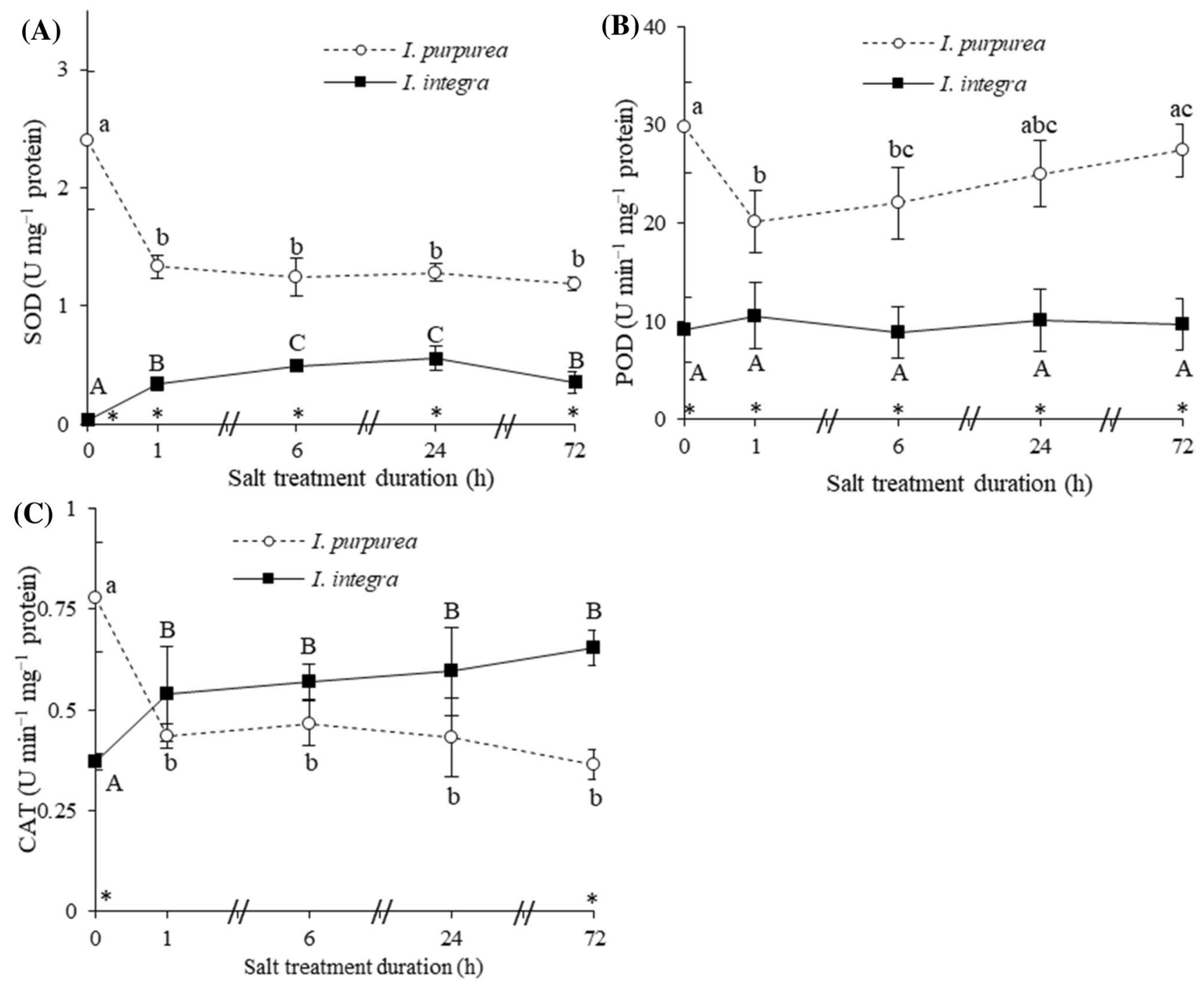

Fig. 6 Activities of SOD a, POD $\mathbf{b}$ and CAT $\mathbf{c}$ in roots of two Ilex species after different durations of salt treatment. An asterisk by the $x$-axis indicates a significant difference in concentration between the two species at that sampling time based on Student's $t$-test $(p<0.05)$.

$\mathrm{Na}^{+}$rapidly accumulated, perhaps due to an ion imbalance or the second phase of the physiological response to salinity (Munns 2002) caused by loss of membrane permeability in the root cells. This result suggests that $I$. integra roots are relatively salt-tolerant and $I$. purpurea root more sensitive to $250 \mathrm{mM} \mathrm{NaCl}$ exposures longer than $24 \mathrm{~h}$. Interestingly, I. integra roots had more than a twofold higher $\mathrm{Na}^{+}$concentration than in I. purpurea roots before the salt exposure (Fig. 1), similar to the report for the halophyte seablite (Suaeda altissima), which has a higher $\mathrm{Na}^{+}$content in roots and leaves than the glycophyte spinach (Spinacia oleracea) does, even when they are both grown in a low $\mathrm{Na}^{+}$medium (0.5 mM) (Meychik et al. 2013). In tomato, the shoot of salt-resistant genotype PI365967 (Solanum pimpinellifolium) contains a higher $\mathrm{Na}^{+}$concentration than
A significant difference among concentrations at the sampling times is indicated by different capital letters for I. integra and by different lowercase letters for I. purpurea based on an ANOVA and Duncan's multiple range test $(p<0.05) .(n=3)$

in the relatively salt-sensitive Moneymaker (Solanum lycopersicum) when grown in 1/4 strength Hoagland control solution, but PI365967 has less $\mathrm{Na}^{+}$in the shoots than in Moneymaker when they are grown in 1/4 strength Hoagland solution with $200 \mathrm{mM} \mathrm{NaCl}$ (Sun et al. 2010). Considering that $I$. purpurea is naturally distributed in the Yangzi River Valley and I. integra grows in coastal regions, the higher $\mathrm{Na}^{+}$level that is present in I. integra without salt exposure compared with its relatively low $\mathrm{Na}^{+}$accumulation in roots during salt stress (Fig. 1) may indicate that its roots evolved to adapt to its natural high-salinity habitat, which, together with other physiological mechanisms, may contribute to its higher root salt tolerance.

To maintain a low intracellular osmotic potential under high salinity, plants may synthesize and accumulate various 
osmolytes, including soluble sugars, proline, hydroxyproline, glycine betaine, polyamines without disturbing the cellular metabolism (Apse and Blumwald 2002; Mansour and Ali 2017). In this study, although soluble sugars did not increase significantly in I. integra roots after salt exposure, they did in I. purpurea roots, which had levels significantly higher than in I. integra roots during the salt exposure (Fig. 3b), indicating soluble sugar may play a role of osmotic regulation in I. purpurea roots. Although initial proline levels did not differ significantly between $I$. purpurea and $I$. integra roots before salt exposure, proline was significantly higher in I. integra roots than in I. purpurea after 1, 6 and $24 \mathrm{~h}$ of salt exposure (Fig. 3a). This result is consistent with previous studies which reported that accumulation of proline is higher in salt-tolerant plant species than in salt-sensitive (Demiral and Türkan 2005; Koca et al. 2007; Kumar and Khare 2016). However, after $72 \mathrm{~h}$ of exposure, the proline level in roots of $I$. purpurea no longer differed significantly from that in I. integra, perhaps indicating that proline accumulation may only be associated with relatively short-term salt stress.

Maintaining the integrity of cell membrane is a major component of plant tolerance to many environmental stresses including salinity (Mansour et al. 2015). In the present study, the levels of malondialdehyde (MDA), as the product of membrane lipid peroxidation, changed similarly over time in the roots of the two species, but were significantly higher in I. purpurea roots than in I. integra roots during salt treatment, indicating more membrane lipid peroxidation in I. purpurea roots. Interestingly, the level of MDA in I. purpruea roots was highest after $24 \mathrm{~h}$ of salt treatment and did not coincide with the sharp increase in $\mathrm{Na}^{+}$concentration at $72 \mathrm{~h}$, indicating that lipid peroxidation is not alone responsible for the sudden $\mathrm{Na}^{+}$influx. Considering that membrane proteins also contribute to plant salt tolerance (Kosová et al. 2013), it would be insightful to compare the proteomics between I. purpurea and I. integra roots during salt exposure to identify any proteins that may be involved in membrane stabilization and ion homeostasis and contribute to the higher salt-tolerance of I. integra (Cheng et al. 2009).

In the present study, the $\mathrm{H}_{2} \mathrm{O}_{2}$ content was found to be significantly higher in I. integra roots than in I. purpurea roots before the salt treatment, but after $72 \mathrm{~h}$ of salt exposure, the level became significantly lower in I. integra roots compared to I. purpurea roots, indicating a higher capacity of I. integra roots for scavenging $\mathrm{H}_{2} \mathrm{O}_{2}$ during salt treatments (Fig. 4).

Plant tolerance to high salinity is known to be associated with higher levels of antioxidant activity needed to scavenge ROS (Jabeen et al. 2020), but contradictory results have also been reported (Bose et al. 2013). In present study, the higher $\mathrm{H}_{2} \mathrm{O}_{2}$ content at $0 \mathrm{~h}$ and lower $\mathrm{H}_{2} \mathrm{O}_{2}$ content after $72 \mathrm{~h}$ of salt exposure (Fig. 4) in I. integra roots was associated with lower CAT activity at $0 \mathrm{~h}$ and a higher CAT activity at $72 \mathrm{~h}$ (Fig. 6c), indicating a potential role of CAT in scavenging $\mathrm{H}_{2} \mathrm{O}_{2}$ during salt stress. In the non-enzymatic ROS scavenging system, ascorbate is thought be the first line of plant defence against oxidative stress (Veljović-Jovanović et al. 2017). Numerous studies on mutant and/or transgenic plants have demonstrated that increased ascorbate levels in certain plants may confer significant abiotic stress tolerance including salinity as reviewed by (Venkatesh and Park 2014). In our study, the total ascorbate pool increased gradually in roots of both species throughout the salt treatment but to a higher level in I. integra roots (Fig. 5a). The content of reduced ascorbate in roots of the two species decreased overall from 0 to $72 \mathrm{~h}$ of salt exposure with no significant difference between two plants at any time except $1 \mathrm{~h}$. At $1 \mathrm{~h}$ of salt treatment, a sharp decreasing of reduced ascorbate was found in I. integra roots, possibly indicating a quicker consumption of reduced ascorbate for efficient ROS scavenging at the beginning stage of salt treatment.

\section{Conclusion}

I. integra roots apparently are relatively more salt tolerant than I. purpurea roots, and the non-enzymatic antioxidant ascorbate and the antioxidative enzyme catalase seem to play substantial roles in scavenging ROS in I. integra roots during salt exposure.

Acknowledgements The authors thank the Baima Experimental Station of Nanjing Forestry University for use of their glasshouse.

Author's contributions $\mathrm{Yu} Y \mathrm{YF}$ and Zhang M contributed equally to this work. Yu YF, Zhang M, Feng JY and Sun SJ performed the experiments and collected data; Yu YF, Zhang $M$ and Yang JD performed the statistical analyses and data visualizations; Zhou P managed plant materials; Yang JD supervised the research and wrote the manuscript. All authors read and approved the final manuscript.

Open Access This article is licensed under a Creative Commons Attribution 4.0 International License, which permits use, sharing, adaptation, distribution and reproduction in any medium or format, as long as you give appropriate credit to the original author(s) and the source, provide a link to the Creative Commons licence, and indicate if changes were made. The images or other third party material in this article are included in the article's Creative Commons licence, unless indicated otherwise in a credit line to the material. If material is not included in the article's Creative Commons licence and your intended use is not permitted by statutory regulation or exceeds the permitted use, you will need to obtain permission directly from the copyright holder. To view a copy of this licence, visit http://creativecommons.org/licenses/by/4.0/. 


\section{References}

Apse MP, Blumwald E (2002) Engineering salt tolerance in plants. Curr Opin Biotechnol 13:146-150

Ashraf M, Foolad MR (2007) Roles of glycine betaine and proline in improving plant abiotic stress resistance. Environ Exp Bot 59:206-216

Bai YC, Xue WJ, Yan YY, Zuo WG, Shan YH, Feng K (2018) The challenge of improving coastal mudflat soil: formation and stability of organo-mineral complexes. Land Degrad Dev 29:1074-1080

Baraldi R, Przybysz A, Facini O, Pierdonà L, Carriero G, Bertazza G, Neri L (2019) Impact of drought and salinity on sweetgum tree (Liquidambar styraciflua L.): understanding tree ecophysiological responses in the urban context. Forests 10:1032

Bates LS, Waldren RP, Teare ID (1973) Rapid determination of free proline for water-stress studies. Plant Soil 39:205-207

Ben Rejeb K, Abdelly C, Savouré A (2014) How reactive oxygen species and proline face stress together. Plant Physiol Biochem 80:278-284

Biswas MS, Mano J (2015) Lipid peroxide-derived short-Chain carbonyls mediate hydrogen peroxide-induced and salt-induced programmed cell death in plants. Plant Physiol 168:885-898

Bose J, Rodrigo-Moreno A, Shabala S (2013) ROS homeostasis in halophytes in the context of salinity stress tolerance. J Exp Bot 65:1241-1257

Bradford MM (1976) A rapid and sensitive method for the quantitation of microgram quantities of protein utilizing the principle of protein-dye binding. Anal Biochem 72:248-254

Campo S, Baldrich P, Messeguer J, Lalanne E, Coca M, San Segundo B (2014) Overexpression of a calcium-dependent protein kinase confers salt and drought tolerance in rice by preventing membrane lipid peroxidation. Plant Physiol 165:688-704

Cavalcanti FR, Oliveira JTA, Martins-Miranda AS, Viegas RA, Silveira JAG (2004) Superoxide dismutase, catalase and peroxidase activities do not confer protection against oxidative damage in salt-stressed cowpea leaves. New Phytol 163:563-571

Cheng YW, Qi YC, Zhu Q, Chen X, Wang N, Zhao X, Chen HY, Cui $\mathrm{XJ}, \mathrm{Xu}$ L, Zhang W (2009) New changes in the plasma-membrane-associated proteome of rice roots under salt stress. Proteomics 9:3100-3114

Demiral T, Türkan I (2005) Comparative lipid peroxidation, antioxidant defense systems and proline content in roots of two rice cultivars differing in salt tolerance. Environ Exp Bot 53:247-257

Diaz-Vivancos P, Faize M, Barba-Espin G, Faize L, Petri C, Hernández JA, Burgos L (2013) Ectopic expression of cytosolic superoxide dismutase and ascorbate peroxidase leads to salt stress tolerance in transgenic plums. Plant Biotechnol J 11:976-985

Eltayeb AE, Kawano N, Badawi GH, Kaminaka H, Sanekata T, Shibahara T, Inanaga S, Tanaka K (2007) Overexpression of monodehydroascorbate reductase in transgenic tobacco confers enhanced tolerance to ozone, salt and polyethylene glycol stresses. Planta 225:1255-1264

Ferguson IB, Watkins CB, Harman JE (1983) Inhibition by calcium of senescence of detached cucumber cotyledons: effect on ethylene and hydroperoxide production. Plant Physiol 71:182-186

Gillespie KM, Ainsworth EA (2007) Measurement of reduced, oxidized and total ascorbate content in plants. Nat Protoc 2:871-874

Gupta B, Huang BR (2014) Mechanism of salinity tolerance in plants: physiological, biochemical, and molecular characterization. Int J Genomics 2014:701596

Hniličková H, Hnilička F, Orsák M, Hejnák V (2019) Effect of salt stress on growth, electrolyte leakage, $\mathrm{Na}^{+}$and $\mathrm{K}^{+}$content in selected plant species. Plant Soil Environ 65:90-96

Hoagland DR, Arnon DI (1950) The water-culture method for growing plants without soil. Calif Agric Exp Station Circ 347:1-32
Jabeen Z, Hussain N, Irshad F, Zeng JB, Tahir A, Zhang GP (2020) Physiological and antioxidant responses of cultivated and wild barley under salt stress. Plant Soil Environ 66:334-344

Kampfenkel K, Vanmontagu M, Inze D (1995) Extraction and determination of ascorbate and dehydroascorbate from plant Tissue. Anal Biochem 225:165-167

Kang Y, Torres-Jerez I, An ZW, Greve V, Huhman D, Krom N, Cui YH, Udvardi M (2019) Genome-wide association analysis of salinity responsive traits in Medicago truncatula. Plant, Cell Environ 42:1513-1531

Koca H, Bor M, Özdemir F, Türkan İ (2007) The effect of salt stress on lipid peroxidation, antioxidative enzymes and proline content of sesame cultivars. Environ Exp Bot 60:344-351

Kosová K, Prášil IT, Vítámvás P (2013) Protein contribution to plant salinity response and tolerance acquisition. Int J Mol Med Sci 14:6757-6789

Kumar V, Khare T (2016) Differential growth and yield responses of salt-tolerant and susceptible rice cultivars to individual $\left(\mathrm{Na}^{+}\right.$and $\mathrm{Cl}^{-}$) and additive stress effects of $\mathrm{NaCl}$. Acta Physiol Plant 38:170

Liu X, Huang B (2000) Heat stress injury in relation to membrane lipid peroxidation in creeping bentgrass. Crop Sci 40:503-510

Liu J, Zhu JK (1997) Proline accumulation and salt-stress-induced gene expression in a salt-hypersensitive mutant of Arabidopsis. Plant Physiol 114:591-596

Locato V, De Gara L (2018) Programmed Cell Death in Plants: An Overview. In: De Gara L, Locato V (eds) Plant Programmed Cell Death: Methods and Protocols. Springer, pp 1-8

Mansour MMF, Ali EF (2017) Evaluation of proline functions in saline conditions. Phytochemistry 140:52-68

Mansour MMF, Salama KHA, Allam HYH (2015) Role of the plasma membrane in saline conditions: lipids and proteins. Bot Rev $81: 416-451$

McCready RM, Guggolz J, Silviera V, Owens HS (1950) Determination of starch and amylose in vegetables. Analyt Chem 22:1156-1158

Meychik NR, Nikolaeva YI, Yermakov IP (2013) Physiological response of halophyte (Suaeda altissima (L.) Pall.) and glycophyte (Spinacia oleracea L.) to salinity. Am J Plant Sci 4:427-435

Munns R (2002) Comparative physiology of salt and water stress. Plant, Cell Environ 25:239-250

Munns R, Tester M (2008) Mechanisms of salinity tolerance. Annu Rev Plant Biol 59:651-681

Noctor G, Foyer CH (1998) Ascorbate and glutathione: keeping active oxygen under control. Annu Rev Plant Physiol Plant Mol Biol 49:249-279

Pang CH, Wang BS (2008) Oxidative Stress and Salt Tolerance in Plants. In: Lüttge U, Beyschlag W, Murata J (eds) Progress in Botany. Springer, pp 231-245

Prashanth SR, Sadhasivam V, Parida A (2008) Over expression of cytosolic copper/zinc superoxide dismutase from a mangrove plant Avicennia marina in indica Rice var Pusa Basmati-1 confers abiotic stress tolerance. Transgenic Res 17:281-291

Roxas VP, Smith RK, Allen ER, Allen RD (1997) Overexpression of glutathione S-transferase/glutathioneperoxidase enhances the growth of transgenic tobacco seedlings during stress. Nat Biotechnol 15:988-991

Roy SJ, Negrão S, Tester M (2014) Salt resistant crop plants. Curr Opin Biotechnol 26:115-124

Ruiz J, Blumwald E (2002) Salinity-induced glutathione synthesis in Brassica napus. Planta 214:965-969

Shi CW, Guo JY, Weng XL, Ma WM, Cao B, Bai XF, Yao R (2019) Seed breeding and cultivation techniques for Ilex purpurea Hassk. J Green Sci Technol 21:116-118 (in Chinese)

Sun W, Xu XN, Zhu HS, Liu AH, Liu L, Li JM, Hua XJ (2010) Comparative transcriptomic profiling of a salt-tolerant wild tomato species and a salt-sensitive tomato cultivar. Plant Cell Physiol 51:997-1006 
Veljović-Jovanović S, Vidović M, Morina F (2017) Ascorbate as a Key Player in Plant Abiotic Stress Response and Tolerance. In: Hossain M, Munné-Bosch S, Burritt D, Diaz-Vivancos P, Fujita M, Lorence A (eds) Ascorbic Acid in Plant Growth, Development and Stress Tolerance. Springer

Venkatesh J, Park SW (2014) Role of L-ascorbate in alleviating abiotic stresses in crop plants. Bot Stud 55:38

Verslues PE, Agarwal M, Katiyar-Agarwal S, Zhu J, Zhu JK (2006) Methods and concepts in quantifying resistance to drought, salt and freezing, abiotic stresses that affect plant water status. Plant J 45:523-539

Wan X, Jiang H, Wang L, He DM, Wang H, Zhu YY (2017) Progress of soil amelioration technology in coastal beach in Jiangsu Province. J Jiangsu Forest Sci Technol 44:43-47 (in Chinese)

Xu BF, Wang GM, Wang MQ, Chen B (2007) Geographic distribution and propagation techniques of Ilex integra and Ilex crenata. Chin Wild Plant Resourc 26:63-65 (in Chinese)
Yang Z, Wang BS (2015) Present Status of Saline Soil Resources and Countermeasures for Improvement and Utilization in China. Shangdong Agric Sci 47:125-130 (in Chinese)

Zhao CZ, Zhang H, Song CP, Zhu JK, Shabala S (2020) Mechanisms of plant responses and adaptation to soil salinity. The Innovation 1(1): 100017

Publisher's Note Springer Nature remains neutral with regard to jurisdictional claims in published maps and institutional affiliations. 